\title{
Investigating Earth's atmospheric electricity: a role model for planetary studies
}

\author{
K.L. Aplin ${ }^{1}$, R.G. Harrison ${ }^{2}$ and M.J. Rycroft ${ }^{3,4}$ \\ 1. Space Science and Technology Department, Rutherford Appleton Laboratory, \\ Chilton, Didcot, Oxon OX11 0QX UK.
}

Corresponding author: email k.l.aplin@rl.ac.uk, fax +44 1235445848

2. Department of Meteorology, University of Reading, Earley Gate, PO Box 243, Reading Berkshire RG6 6BB UK

3. International Space University, 1 rue Jean-Dominique Cassini, 67400 IlkirchGraffenstaden, France

4. CAESAR Consultancy, 35 Millington Road, Cambridge CB3 9HW, UK

\begin{abstract}
The historical development of terrestrial atmospheric electricity is described, from its beginnings with the first observations of the potential gradient to the global electric circuit model proposed by C.T.R. Wilson in the early $20^{\text {th }}$ century. The properties of the terrestrial global circuit are summarised. Concepts originally needed to develop the idea of a global circuit are identified as "central tenets", for example, the importance of radio science in establishing the conducting upper layer. The central tenets are distinguished from additional findings that merely corroborate, or are explained by, the global circuit model. Using this analysis it is possible to specify which observations are preferable for detecting global circuits in extraterrestrial atmospheres. Schumann resonances, the extremely low frequency signals generated by excitation of the surface-ionosphere cavity by electrical discharges, are identified as the most useful single measurement of electrical activity in a planetary atmosphere.
\end{abstract}

\section{Keywords}

92.60.Pw Atmospheric electricity, lightning

01.65. $+g \quad$ History of science

96.30.BC Comparative planetology

96.15.Hy Planetary atmospheres

\section{Historical Introduction}

The understanding of electricity is a relatively recent development in human endeavour, although lightning is known to have existed on Earth for much longer than homo sapiens. Lightning will almost definitely have been known to all human civilisations, some of whom recorded it in their literature, or linked the phenomena with gods unleashing thunderbolts. According to Schiffer (2003), William Gilbert (1540-1603), the physician to Queen Elizabeth I, was the first person to investigate electrical phenomena in what is now referred to as a "scientific" way. It was known amongst natural philosophers that amber and other insulators could attract straw fragments and chaff, but Gilbert was first to identify that it was only lightweight items that were subject to the mysterious attraction, and to generalise the types of material that could act as attractors. 
The study of what might now be called electrostatics progressed throughout the seventeenth and eighteenth centuries (Schiffer, 2003), through the development of scientific instrumentation such as the Leyden jar (Falconer, 2004) and also the start of scientific academies such as the Royal Society (London) and the Académie des Sciences (Paris). Benjamin Franklin (1706-1790), the famous American polymath, is credited with suggesting that lightning was electricity, proposing an experiment later undertaken by Thomas-Francois d'Alibard (17031799 ) in 1752, who extracted sparks from a cloud. As well as making further measurements under thunderstorms, John Canton (1718-1772) observed in experiments in England that electricity was also present in cloudless air (Canton, 1752). In the late eighteenth century a two-year series of quantitative atmospheric electrification measurements was made by John Read (1726-1814), who monitored, at least daily, the deflection of a pith ball electrometer connected to an insulated mast on the roof of his house in Knightsbridge, London (Read 1791). This monitoring approach was inspired by the earlier work of Giovanni Battista Beccaria (1716-1781) in Piedmont, Italy (Beccaria 1775). Beyond static electricity, the possibility of charge flow was emerging from laboratory experiments at around the same time. Charles-Augustin Coulomb (1736-1806) noticed that the charge on an object slowly decayed in air with time, and that this decay was more rapid when the air was more humid:

L'électricité des deux balles diminue un peu pendant le temps que dure l'experience... si l'air est humide et que l'électricité se perd rapidement... (Coulomb, 1784)

For this Coulomb is widely credited with discovering the electrical conductivity of air, though it is not clear that he realised the significance of his findings. He certainly did not have the theoretical understanding to explain the effect, as will be explained. To Coulomb, an experimentalist, the conductivity of air was just another difficulty encountered during his investigations of the inverse square law of electrostatic repulsion.

Detailed observation, but a lack of explanatory power, was a characteristic of this early work. Scientific theory did not exist to explain the electrical conductivity of gases until the discovery of the electron over a hundred years later. Similarly, the lack of an explanatory framework for an atmospheric electric potential in the absence of electrified cloud, which was well-established by the mid-nineteenth century, precluded systematic study of the phenomena. For example, early experimenters had noted that an atmospheric measuring electrode developed a positive charge during fine weather (Bennett and Harrison 2007), and that it varied considerably with the weather conditions, but Beccaria's suggestion that it might one day be possible to use atmospheric electricity for weather prediction was drawn only from experience rather than a theoretical understanding. At this stage, therefore, the theory did not exist to permit a more sophisticated approach than simple inductive empiricism.

In the nineteenth and early twentieth centuries the study of atmospheric electricity was approached more systematically. With scientific giants such as Faraday and Maxwell researching electricity and electromagnetism, a better physical context for the measurements was starting to be developed. The advent of more reliable instrumentation and, in particular, the ability to make continuous automatic 
measurements of the atmospheric electric field (more conventionally now known as the Potential Gradient, $\mathrm{PG}^{1}$ ), was very important during this period. Lord Kelvin $^{2}$ (1824-1907) was one of the pioneers of this autographic recording, developing an electrometer that measured the PG by letting water dribble through a pipe from an isolated tank, which, through charge exchange, caused the tank to acquire the potential of the atmosphere where the stream broke into a droplet spray. Kelvin's "water dropper" was used with photographic recording to produce continuous atmospheric electrical measurements for the first time in 1862 (Everett, 1868). As a result, Kelvin concluded that electrification was a property of the fair weather atmosphere. This equipment began continuous measurements of the atmospheric PG in the UK at Kew Observatory ${ }^{3}$ (Harrison and Aplin 2002), and at new scientific research facilities such as at the top of the Eiffel Tower in Paris (Harrison and Aplin 2003).

As well as surface measurements, new opportunities were presented by manned balloons which provided measurements of PG above the surface (Table 1). However, it was not just the PG that was measured. After the almost simultaneous discovery of the electron and ionising radiation (X-rays and radioactivity) in the last years of the nineteenth century, study of the conduction of electricity in gases progressed rapidly. Most of this work was carried out at the Cavendish Laboratory at Cambridge, first under J.J. Thomson (1856-1940), and then Lord Rutherford (1871-1937). It was during this period that many of the terms used to characterise ions in air were defined, for instance, the concept of mobility (the speed of an ion at terminal velocity in a unit electric field) (Aplin 2000). In parallel with the Cavendish laboratory studies, in Europe, Ebert, Gerdien, Elster and Geitel developed instrumentation to measure atmospheric ions in situ (Elster and Geitel 1900; Ebert 1901; Gerdien 1905). Gerdien's instrumentation permitted the air conductivity to be measured on balloon ascents, providing further data on ion properties (Table 1). Wigand's ascent was one of the first to measure reliably both PG and conductivity to $9 \mathrm{~km}$. This permitted determination of the conduction current, which was found to be essentially independent of height in the free troposphere (Wigand, 1914, 1921; Wigand and Everling, 1921).

\section{[insert Table 1]}

The beginning of the twentieth century is often considered to mark a transition between "classical" and "modern" physics. Atmospheric electricity also moved into a new phase at this time. There was new instrumentation with which to make systematic measurements of spatially varying quantities, supported by the rapid advances in contemporary physical theory. This set the scene for unification of previously disparate measurements, through the concept of the global circuit. The development of the global circuit model will be outlined in Section 2 followed by more detail on its properties and parameters in Section 3. The final Discussion section will conclude by summarising the historical development of the terrestrial global circuit and outlining its application to planetary studies.

\footnotetext{
${ }^{1}$ The potential gradient (PG) and electric field have equal magnitudes, but are of opposite sign by convention. In fair weather, when the vertical electric field is negative, the PG is considered positive.

${ }^{2}$ Lord Kelvin was formerly W. Thomson and his papers are listed under this name.

${ }^{3}$ Observations at Kew continued virtually uninterrupted from 1860 until 1981, although their absolute calibration improved (Harrison, 2003).
} 


\section{Development of the global circuit concept}

From the studies in the eighteenth and nineteenth centuries, basic facts of atmospheric electricity emerged. By the beginning of the twentieth century it was well-established that:

(1) a positive potential gradient was present in fair weather,

(2) ions were formed naturally in air,

(3) air had a finite electrical conductivity (known originally as the property of "dissipation").

It was known that the PG and conductivity were inversely related (Gockel 1903; Zolss 1904), and this result was extended by Simpson (1906a) to be related to "clarity" (visibility) of the air. Simpson (1906b) remarked that, from balloon ascents, the observed reduction in PG provided an inference that charge existed through the lower layers of the atmosphere. The balloon ascents of Gerdien, Wigand, and others found, from PG and conductivity measurements, that the airEarth conduction current was constant with height. This provided evidence of current flow in an electric field between the upper atmosphere and the surface. C.T.R. Wilson (1869-1959) developed new apparatus for direct measurements of the air-Earth current, which was able to make measurements in different conditions without precipitation ${ }^{4}$ (Wilson 1906, 1908).

The mechanism to sustain the current observed in fair weather was a matter of scientific speculation, though it was known to be generated within the atmosphere (Simpson 1906b). Wilson $(1921,1929)$ proposed that thunderstorms and rain clouds provided the current. It was possible to consider current flow from distant storms to fair weather regions, as the conductive properties of the upper atmosphere had then been deduced from radio wave studies. This will be discussed further in Section 4.1.

A test for the theory that the thunderstorms, highly conductive ionosphere and surface, and partially conductive lower atmosphere together constituted a global atmospheric electrical circuit (the "Wilson circuit") came from the cruises of the geophysical research ship Carnegie in the 1920s. During these voyages, a characteristic daily variation (with Universal Time) of the atmospheric PG known as the Carnegie curve - was found; it was noted that this was largely independent of the global position of the ship. (Oceanic air was particularly favourable for these measurements, because of its remoteness from continental aerosol pollution.) Using thunderday ${ }^{5}$ statistics (Brooks 1925) from meteorological stations, and summing the diurnal variations in thunderstorm area for each of Africa, Australia and America, a strong positive correlation was found between the Carnegie curve and the diurnal variation in global thunderstorm area ${ }^{6}$ (Whipple 1929; Whipple and Scrase 1936). Seasonal changes in the Carnegie curve variations are considered in Rycroft et al. (2008).

\footnotetext{
${ }^{4}$ These were continued in a very similar manner by the UK Met Office between 1909 and 1979 (Harrison and Ingram, 2005).

${ }^{5}$ A thunderday is a calendar day on which thunder is heard at a meteorological observing station.

${ }^{6}$ The original Carnegie and thunderday data is tabulated in Harrison (2005)
} 
These findings confirmed one of the predictions of a global circuit hypothesis, namely that the variations in PG were linked to the electrical activity of thunderstorms elsewhere on the planet. Further evidence for the global circuit was provided when measurements of the ionospheric potential $V_{\text {I }}$ were obtained in the late 1950s, by integration of the vertical PG profile using balloon or aircraft carried field sensors (Imyanitov and Chubarina 1967; Markson 2007). Soundings made by Mülheisen (Budyko 1971) from Weissenau, Germany between 1959 and 1972 included a period in March-April 1967 that showed common simultaneous variations in $V_{I}$ measured over Weissenau and above the research ship Meteor in the Atlantic (Mülheisen 1971). The same $V_{I}$ measurements made over the Atlantic have been shown to correlate closely with surface measurements of PG made at Lerwick, Shetland Islands, UK (Harrison and Bennett 2007). Simultaneous variations of $V_{\mathrm{I}}$ at two locations coupled with synchronous changes in the PG provide important support for the global circuit concept. The existence of a Carnegie-like diurnal variation in $V_{\mathrm{I}}$ (Mülheisen 1977) provides further confirmation of the coupling and integrating properties of the global circuit.

\section{Properties of the global electric circuit}

The Earth possesses, on average, a surface which is a good conductor of electricity. Land conductivity ranges from $10^{-8} \mathrm{Sm}^{-1}$ for marble up to $\sim 10^{-2} \mathrm{Sm}^{-1}$ for wet clay or limestone, a typical mean value being $10^{-2} \mathrm{Sm}^{-1}$ (Lowrie 2007); the main mechanism of crustal conduction is through impurity semi-conduction in dry silicate rocks. The ocean conductivity ranges from 3 to $4 \mathrm{Sm}^{-1}$, depending on salinity and temperature, the mean value being $\sim 3.2 \mathrm{Sm}^{-1}$ (Olsen and Kuvshinov 2004). Kamra and Ravichandran (1993) point out that the Earth's surface cannot universally be considered a conductor, particularly in hot dry areas and at the poles, where the land conductivity $<10^{-9} \mathrm{Sm}^{-1}$. However, this is not thought to be important for the global circuit due to the specific geographical regions concerned combined with the paucity of lightning over the less conductive surface regions. At altitudes above $\sim 80 \mathrm{~km}$, the ionospheric plasma produced by the action of solar extreme ultraviolet and X-radiation on the tenuous upper atmosphere is also a good conductor of electricity (Schunk and Nagy 2000). Between these two conductors lies the atmosphere, which behaves like a leaky insulator (an imperfect dielectric), as discussed by Rycroft et al. (2000), Williams (2002, 2007), Harrison (2004), Rycroft (2006) and Markson (2007). The atmospheric conductivity increases with height as the ionisation produced by cosmic rays increases, from a surface value of $\sim 10^{-14} \mathrm{Sm}^{-1}$ (mostly from natural radioactivity emanating from the Earth) by seven orders of magnitude, to reach the large values $\left(\sim 10^{-7} \mathrm{Sm}^{-1}\right)$ characterising the electrically conducting ionosphere.

Complex microphysical processes acting within thunderclouds generally cause the build up of reservoirs of positive electric charge at $\sim 10-16 \mathrm{~km}$ altitude and, in regions well below these, reservoirs of negative charge; a vertical electric dipole is thereby formed. Details of the physical mechanisms operating are given in Yair (2008) and Saunders (2008), and more complicated geometrical arrangements of charge - multipoles - often exist in a thundercloud. These thunderclouds constitute giant "batteries" which drive an upward current (i.e. positive ions moving upwards, and negative ions moving downwards) through the stratosphere and mesosphere up to the ionosphere, as was first discussed in the seminal paper by Wilson (1921). This upward thunderstorm conduction current contributes to 
causing the potential of the ionosphere to reach $\sim+250 \mathrm{kV}$ with respect to that of the Earth's surface. As a good electrical conductor, the ionosphere is an equipotential surface which is approximately spherically symmetric about the Earth.

Remote from thunderstorms, in the so called "fair weather" regions of the globe, an electric current flows downwards through the atmosphere to the Earth; positive ions move downwards and negative ones upwards. The value of the vertical conduction current density $J_{\mathrm{c}} \sim 2 \mathrm{pAm}^{-2}$ (Wilson 1906, Wahlin 1994, Rycroft et al. 2000, Markson 2007). The current flowing in this DC global circuit is closed by point discharge currents (sometimes termed coronal currents) which are created in the large electric fields existing below thunderclouds, as was first pointed out by Wilson (1921). These processes are illustrated in Figure 1, taken from Rycroft and Füllekrug (2004). This figure was originally produced to introduce the activities of the SPECIAL (Space Processes and Electrical Charges Influencing Atmospheric Layers) Scientific Network of the European Science Foundation. The arrows show the electric currents flowing through the global atmospheric electric circuit. Further, Figure 1 indicates that the ionosphere and atmosphere below it respond to heliospheric phenomena, such as the solar wind flowing radially away from the Sun at $\sim 400 \mathrm{kms}^{-1}$, energetic charged particles precipitating from the magnetosphere, and also to cosmic rays coming from beyond the solar system.

\section{[insert Figure 1]}

Figure 1 also shows lightning discharges from the top and from the bottom of a thundercloud to ground; these radiate electromagnetic waves across the spectrum from Extremely Low Frequency (ELF, $3 \mathrm{~Hz}$ to $3 \mathrm{kHz}$ ), and Very Low Frequency (VLF, 3 to $30 \mathrm{kHz}$ ) to High Frequency (HF, 3 to $30 \mathrm{MHz}$ ). At Ultra Low Frequency (ULF, $<3 \mathrm{~Hz}$ ) lightning generates transient signals (see Fukunishi et al. 1997); pulsations at ULF are generated in the magnetosphere. Lightning acts as a source of electromagnetic radiation which excites the AC global circuit; Schumann resonances of the Earth-ionosphere cavity exist at frequencies of 8, 14, $20,26, \ldots \mathrm{Hz}$ (Simoes et al. 2008). Above the thundercloud is shown a sprite, a type of upward lightning discharge - for details of sprites and associated phenomena, see Füllekrug et al. (2006), Mika and Haldoupis (2008) and Mishin and Milikh (2008).

Other than thunderstorms, there are two further major mechanisms which act as drivers for current flows around the global electric circuit. Interactions between the solar wind and the Earth's magnetic field generate additional currents (Rycroft et al. 2000), and PG modulation may arise from coupling of geomagneticallyinduced changes in the magnetospheric dynamo through the global circuit. These perturbations generate polar cap potential differences, which can cause surface PG variations of $\pm 20 \%$ (Roble and Tzur 1986). The ionospheric/magnetospheric generator is thought only to affect the global circuit appreciably at high latitudes, although weak geomagnetic influences have been detected at lower latitudes (Märcz, 1976; Harrison and Märcz 2007). Another process driving current around the global circuit is precipitation (commonly called "rain") from electrified clouds (Wilson 1921, Williams and Heckman 1993). A cloud transferring negatively charged water droplets constitutes another "battery" which causes currents to flow 
in the same direction as does the thundercloud mechanism already discussed. The total current flowing in the global atmospheric electric circuit $\sim 1-2 \mathrm{kA}$. Together with its physical dimensions (the Earth's radius $=6378 \mathrm{~km}$, and the base of the ionosphere at $\sim 80 \mathrm{~km}$ ), it is the profiles of the atmospheric conductivity at all locations over the Earth which determine, via Ohm's law, the properties (namely, the electric fields and current densities everywhere) of the global atmospheric electric circuit. An "electrical engineering" model of the circuit, originally involving only resistors, was devised by Markson (1978). Some more realistic models, with capacitors as well as resistors (see Rycroft 2006, Rycroft et al. 2007), are introduced in Rycroft et al. (2008). A simplified model of the global circuit is shown in Figure 2.

\section{[insert Figure 2]}

Any of the electrical processes operating in the Earth's climate system may respond to climate change (i.e. global warming or, specifically, increased concentrations of greenhouse gases in the atmosphere). There is also the possibility that sensitive components of the climate system can respond to atmospheric electrical changes. One sensitive aspect of the climate system is clouds.

It has been suggested that changes in the electrical properties of the atmosphere could alter the properties of clouds, resulting in a climate response. Plausible possible mechanisms have been discussed by Carslaw et al. (2002). In one scenario (the "ion-aerosol clean air mechanism"), cluster ions contribute to the formation of aerosol particles in clean air, on which cloud droplets subsequently form; in another scenario (the "ion-aerosol near cloud mechanism"), the atmospheric electrical conduction current causes particle and droplet charging which modify the cloud properties.

The clean air mechanism is illustrated in Figure 3. In this process, condensation of vapour on freshly-formed cluster ions leads to the formation of new ultrafine particles. Laboratory and atmospheric evidence exists which demonstrates that, in the absence of other sinks of the condensable vapour, such ultrafine particle formation can occur. Ultrafine particles are not, however, able to form water clouds because of their small size. A particle needs to reach $100 \mathrm{~nm}$ radius to permit condensation of water in atmospheric conditions - known as a Cloud Condensation Nucleus (CCN) - but the ultrafine particles formed are about two orders of magnitude smaller. The growth stage of the ultrafine particles is therefore critical, if there is to be a later influence on the formation of cloud droplets. Modelling by Yu and Turco (2001) indicates that the growth timescale is typically 5 to 10 hours.

\section{[insert Figure 3]}

The near cloud mechanism results from the difference in electrical conductivity of air within and outside a cloud. In the simple case of a horizontal layer cloud, charge accumulates at the cloud boundary with clear air, as a result of the vertical current density within the global circuit (Figure 4). The effect of charge on cloud has not been investigated in detail, but, for the special case of supercooled water clouds, Tinsley and Heelis (1993) suggested that electrification might enhance the 
effectiveness of aerosol as ice-forming nuclei - which are relatively rare in the atmosphere - and therefore the amount of cloud ice formed. This was called electrofreezing. A possible mechanism for electrofreezing is the electricallyenhanced collection of charged ice nuclei by supercooled water droplets, which has been quantified through detailed modelling (Harrison 2000; Tripathi 2000; Tinsley et al. 2001; Tripathi and Harrison 2002; Tripathi et al. 2006). Such an electrically-enhanced aerosol scavenging process, known as electroscavenging, may lead to electrofreezing on the cloud boundary. There are laboratory observations of electroscavenging, but no direct atmospheric observations of electrofreezing. If electrofreezing does occur, there could be appreciable local latent heat release. As indicated on the right hand side of Figure 4, the charge density on the cloud boundary is proportional to the vertical current density flowing in the global circuit. Harrison and Shine (1999) and Tinsley (2000) suggested that the global circuit may be involved in climate change via electrical effects on cloud microphysical processes in fair weather regions.

\section{[insert Figure 4]}

The global circuit model has recently been extended by Rycroft et al. (2007) to include the generator associated with electrified clouds; this was found to be of the same magnitude as that due to thunderstorms. Further refinements of the model could be attempted. Rycroft et al. (2007) also showed that a sprite (Füllekrug et al. (2006); Mika and Haldoupis (2008); Mishin and Milikh (2008)) following a cloud to ground lightning flash which transports positive charge to ground varies the ionospheric potential in only a miniscule way. However, the effects of gigantic jets (Pasko et al. 2002; Su et al. 2003) on the ionosphere and the global atmospheric electric circuit have yet to be modelled.

\section{Discussion}

Based upon many observations performed and experiments conducted in the Earth's atmosphere over the last 250 years, the concept of a global atmospheric electrical circuit is one which orders the diverse measurements satisfactorily and is able to explain subsequent findings adequately. Though it still has some inadequacies - notably the absence of upper atmosphere discharges and no allowance for electron density variations in the ionosphere - it still provides the best overall model available with which to unify the many disparate measurements and theoretical concepts associated with electricity in the atmosphere. Recently, other approaches to understanding the global circuit, such as simple "electrical engineering" models (e.g. Figure 2), have provided a reasonable theoretical framework within which atmospheric electrical phenomena can be understood.

Starting from the origin of electrostatics with William Gilbert in the $16^{\text {th }}$ century, the concept of a global circuit took around four hundred years to emerge in the $20^{\text {th }}$ century; it is arguably still incomplete. As the word "theory" implies a still greater level of predictive power (Hesse 2000), the global circuit is referred to throughout this paper as a "model" or a "concept". In this section the development of the model is discussed so that the key concepts can be identified and used to prescribe the simplest possible measurements that could detect an extraterrestrial global circuit. 


\subsection{Concepts needed in originating the idea of a global circuit}

The findings leading to the development of the global circuit model were discussed in Sections 1 and 2 above. They can be categorised into concepts that were absolutely necessary for the model to be established, and those that support or are supported by the global circuit model, but were not essential to establish it. Here the two types of finding are defined as "central tenets" and "confirming ideas", summarised in Figure 5.

\section{[insert Figure 5]}

Chronologically, the first central tenet to be established was the existence of a positive potential gradient in all fair weather regions. Kelvin was probably one of the earliest to become aware of the ubiquity of the PG through his own measurements, and a compilation of the many disparate observations described in Section 1. For example, he described Beccaria's, "incessant observations on atmospheric electricity, night and day, sleeping in the room with his electrometer in a lofty position" (Thomson 1859, Harrison and Bennett 2007). As is also described in Section 1, the conductivity of the air was observed but not explained by Coulomb (1784) and attributed to the continual formation of ion pairs in air by Wilson $(1897,1899)$.

The next central tenet came from the discovery of cosmic rays by Hess (1912) through atmospheric soundings. This was important for development of the global circuit model, since it explained how ionisation was sustained throughout the entire atmosphere. Contemporary experimenters such as those within the Cavendish in Cambridge were well aware of the contribution of radioisotopes to air ionisation at the surface but, if radioactivity was the only source of atmospheric ionisation, air conductivity would become negligible above $\sim 1 \mathrm{~km}$. Hess's historic balloon ascent showed that "penetrating radiation", a uniquely persistent form of ionising radiation that could not be screened out like other forms of radioactivity, came from outside Earth's atmosphere.

Two further central tenets for the global circuit model were the conducting upper and lower layers, needed to sustain current flow from thunderstorm regions around the Earth. The development of these concepts is intimately linked with the history of radio science. Besser (2007) explains that the first postulation of an upper conducting layer followed from Gauss's expansion of spherical harmonics for the Earth's magnetic field in 1839, and it was later suggested by several $19^{\text {th }}$ century scientists, such as Kelvin in 1860, and Balfour Stewart in 1882, who is often credited with proposing the idea (e.g. Simpson 1941). Fitzgerald publicly conjectured the existence of a conducting layer high in the atmosphere at a British Association meeting in 1893. In the same presentation, he presciently proposed that thunderstorms could be the excitation mechanism (Besser 2007). Fitzgerald's suggestions could also have been inspired by discussions with his friend Lodge, who gave the first public demonstration of radio transmission at a subsequent British Association meeting in 1894 (Lovell 1997). The observation of this conducting layer, however, needed long-distance radio transmission. Radio transmission beyond line of sight requires the existence of an ionised layer in the upper atmosphere to reflect the radio waves around the Earth. Marconi was internationally recognised for transmitting a radio signal across the Atlantic in late 1901 (Franklin 1902), using technology largely developed by Lodge, to 
demonstrate potential for the commercial development of radio. Marconi's achievement was first explained in terms of this conducting layer by Kennelly, and, independently and slightly later, Heaviside (Heaviside 1902; Kennelly 1902; McAdie 1925). The lowest ionospheric conducting region was subsequently named the Kennelly-Heaviside layer.

As implied in Section 3, the Earth's surface also needs to be conductive relative to the atmosphere for a global circuit to exist. A finite surface conductivity had been assumed for many years simply based on the mean conductivity of the salt water covering most of the planet. Chapman (1919), building on investigations of the terrestrial magnetic field, was first to calculate the Earth's surface conductivity accurately, stating that it was "similar to that of moist earth".

C.T.R. Wilson himself had developed the instrumentation to establish the next central tenet: the vertical fair weather current $(1906,1908)$. His work on what became the global circuit seems to have begun around the same time, no doubt inspired by the same fascination with the weather that motivated the cloud chamber work for which he ultimately became famous (Galison 1997). As early as January 1909, Wilson's notebooks show he was trying to understand where the Earth's negative charge (which can be deduced from the direction of the fair weather PG) came from, "It is conceivable that negative charge might be continually acquired to earth by beta rays from atmosphere" (Wilson 1909). Wilson (1909) rejected an experimental test of this idea due to the impossibility of excluding "penetrating radiation". In notes on a paper by Simpson (1909), Wilson (1909) realised that charge was carried downwards by rain. This is the one of the building blocks of the global circuit model, but the ionising upper layer, of which Wilson does not seem to have been aware in 1909, is needed to "close" the circuit $^{7}$. In Wilson's 1921 paper the first principles of the global circuit model are presented:

Thus far no account has been taken of the conducting layer in the higher levels of the atmosphere, to the existence of which the phenomena of terrestrial magnetism seem to point.

The normal potential gradient at the surface of the ground in clear weather is of the order of 100 volts per metre, falling off with increasing height and becoming negligible above $10 \mathrm{~km}$; thus the potential in the conducting layer over regions of fine weather is not likely to exceed a value of the order of 1,000,000 volts. If we assume...that the conductivity of the upper atmosphere is high enough to prevent any large potential differences within it, then even above a thunderstorm the potential in the conducting layer may not greatly exceed 1,000,000 volts.

(Wilson 1921)

The final unifying concept, of the fair weather current balancing the current flow from thunderstorms and other electrified clouds (referred to slightly ambiguously by Wilson as "shower clouds") is sketched out in notebooks of the 1920s (Wilson 1926) and presented in the second global circuit paper (1929):

\footnotetext{
${ }^{7}$ It is possible that Wilson could have learnt about the ionising upper atmosphere from conversations with E. V. Appleton (1892-1965) who was based in the Cavendish Laboratory from 1920-1924. In the cramped surroundings of the old laboratory in Free School Lane, interactions on topics of mutual scientific interest would seem very likely.
} 
I have long held that we must look to showers and thunderstorms as the main agents in the maintenance of the negative charge on the earth in fine weather regions; that they act as electric generators which remove positive electricity from the earth and supply it to the conducting upper atmosphere by which it is distributed over the whole earth. The upper atmosphere is thus maintained at a potential of nearly one million volts... There are on average nearly 2,000 thunderstorms in action at a given moment. An upward current of one ampere per thunderstorm would be more than sufficient to balance the downward current of the fine weather regions.

(Wilson 1929)

In this paper Wilson refers to Brooks' (1925) thunderday data and the results from the Carnegie voyages (discussed here in Section 2). As shown in Figure 5, these measurements were not actually necessary for development of the global circuit concept, but it is likely that Wilson took them as corroboration of the validity of his "long held" ideas. Subsequent work has continued to validate and elaborate Wilson's model, as was described in Section 2.

\subsection{Detection of planetary atmospheric global circuits}

The concept of a global atmospheric electric circuit is of value in studies both of terrestrial and planetary atmospheres. In the last decade it has been suggested that other planets could have a global circuit, with Mars as the prime candidate (Aplin 2006). In this final section a comparative approach will be used to suggest what could be learnt about other planets based on terrestrial atmospheric electricity. A more systematic study of extraterrestrial global circuits will also be proposed based on the experience gained from development of the terrestrial circuit.

The existence of physical mechanisms linking the terrestrial global circuit with climate is vigorously debated, as summarised in Section 3. A key role for the global circuit is that it continuously distributes ions throughout the atmosphere, and moves freshly-formed ions vertically in the fair weather conduction current. Such a transfer of ions may introduce ions to regions where the ions grow, and new particle formation results. In addition, electrical transport could be important for some trace chemical species, particularly in extraterrestrial atmospheres where other transport mechanisms (e.g. convection) can be less important. On Earth, the global circuit forms part of a linking framework between the sun, space, and upper and lower atmosphere. Recent analysis of a long series of terrestrial potential gradient measurements shows that a quasi-periodicity known to be generated in the heliosphere (at 1.68years) is also present in surface atmospheric electricity: should the common periodicities indeed have the same origin this provides direct evidence for the global circuit acting to couple heliospheric changes with the lower troposphere (Harrison and Märcz 2007). The relevance of electrical processes to the climate in extraterrestrial planetary atmospheres is more likely where solar radiation plays a more minor role, such as on Titan. Here, electrical interactions may control, for example, cloud formation and lifetime (Aplin 2006).

To define the optimal measurements to be made in another planetary environment, it is helpful to remember what defines a global circuit. The necessary 
requirements have been discussed elsewhere (e.g. Aplin 2006) and can be briefly summarised as:

- an upper conductive layer

- a lower conductive layer

- discharges or precipitation, to "charge" the circuit

- current flow in fair weather, to "discharge" the circuit

Detection of all these aspects is necessary to establish the existence of a planetary global circuit. (This should be distinguished from the central tenets discussed in Section 4.1 needed to originate the concept of a global circuit). Table 2 shows which of these necessary parameters could be detected by measurements made from an orbiter or in situ. It is clear that Schumann resonance measurements are by far the most valuable single atmospheric electrical observation, since the existence of the Schuman resonance requires the existence of both upper and lower conducting layers, and electrical discharges for excitation (see e.g., Simoes et al. 2008). If Schumann resonances are detected, then only one further factor of vertical current flow is needed to confirm the existence of a global circuit. Nondetection of the Schumann resonances does not show there is no global circuit, as it is possible to have a circuit in which charge is only transferred by precipitation, with no discharges to excite the cavity. Measurement of Schumann resonance is most likely to result from in situ instrumentation, though it may be possible from an orbiter alone, through sensitive detection of leakage of the ELF radiation outside the cavity. At the moment there is no established remote sensing technology to measure vertical current flow (though this may ultimately be achieved through detection of charged species using their infra-red absorption properties (Aplin and McPheat 2005). In situ measurements are therefore necessary for the unambiguous identification of a global circuit.

\section{[insert Table 2]}

The only in situ extraterrestrial atmospheric electrical measurements so far, made in Titan's atmosphere during the descent of the Huygens probe in 2005, may have detected a Schumann resonance frequency at $36 \mathrm{~Hz}$, though it is not yet established beyond doubt (Simoes et al. 2007; Béghin et al. 2007). The excitation mechanism is uncertain due to the probable rarity of electrical discharges; however, it is still possible that Titan could have a global circuit with precipitation as the major charge carrier (Owen et al. 2007), if the surface is adequately conductive compared to the atmosphere close to the surface. This surface-lower atmosphere conductivity ratio could be important, since on Earth it is very high $\left(\sim 10^{12}\right)$ whereas the other "terrestrial" planets tend to have more conductive lower atmospheres and less conductive surfaces e.g. the same ratio for Mars $\sim 100$. Future in situ measurements currently planned for the ExoMars mission, e.g. a radio instrument and an electric field detector (Berthelier et al. 2000), should contribute to understanding some of these issues.

The classical Wilson global circuit model can probably only be applied to "Earthlike" planets or moons, with a well-defined surface and atmosphere, principally Venus, Mars and Titan. It is likely that very different circumstances, at, for instance, the giant planets, where there is no solid surface, will make any global circuit work in an entirely different way (Aplin, 2006). For example, recent observations from the Cassini spacecraft suggest coupling between Saturn's 
thunderstorms and rings (Jones et al. 2006); this can only hint at the surprises planetary atmospheric electrical systems may have in store.

\section{Acknowledgements}

K.A. Nicoll (University of Reading) provided Figure 2. K.L. Aplin was partially supported by the U.K. Science and Technology Facilities Council.

\section{References}

C. Andre, Comptes Rendus 117, 729-732 (1893)

K.L. Aplin, Instrumentation for atmospheric ion measurements, PhD Thesis, The University of Reading, UK (2000)

K.L. Aplin, Surv. Geophys., 27, 63-108 doi: 10.1007/s10712-005-0642-9 (2006)

K.L. Aplin, R.A. McPheat, J. Atmos. Sol-Terr Phys, 67, 8-9, 775-783

doi:10.1016/j.jastp.2005.01.007 (2005)

G. Beccaria, Della elettricite terrestre atmosferica a cielo serno (Turin, 1775)

C. Béghin, F. Simões, V. Karnoselskhikh et al, Icarus, 191, 1, 251

doi:/10.1016/j.icarus.2007.04.005 (2007)

J.J Berthelier, R. Grard, H. Laakso et al, Planet. Space Sci. 48, 12-14, 1193-1200 (2000)

A.J. Bennett, R.G. Harrison, Weather 62, 10 doi: 10.1002/wea.97 (2007)

B.P. Besser, Radio Sci., 42, RS2S02, doi:10.1029/2006RS003495 (2007)

C.E.P. Brooks, Geophys. Memo. 3, 24, 147-164 (1925)

M.I. Budyko, Results of observations of atmospheric electricity (The World Network, Additional Issue 1965-1969). (USSR Chief Administration of the Hydro-Meteorological Service, Leningrad, 1971)

J. Canton, Phil. Trans. 48, 780-785 (1753)

K. S. Carslaw, R. G. Harrison, J. Kirkby, Science 298, 1732 (2002)

S. Chapman, Phil. Trans. Roy. Soc. Lond A., 218, 1 (1919)

B. Chauveau, Electricité Atmosphèrique, vol. 3. (Libraire Octave Doin, Paris, 1925)

C.A. Coulomb, Collection de mémoires relatifs à la physique, Tome I. (Gauthier-Villars, Paris, 1784), pp113-114 (Available online at http://cnum.cnam.fr/fSYN/8CA121-1.html)

H. Ebert, Phys. Z. 2, 662-664 (1901)

J.E. Elster and H. Geitel, Phys. Z, 2, 116 (1900)

J.D. Everett, Phil. Trans. Roy. Soc. Lond., 158, 347-361 (1868)

E. Everling, A. Wigand, Annal. der Physik 66, 20, 261-282 (1921)

I. Falconer, Metrologia 41 S107-S114 (2004)

W.S. Franklin, Science, 15, 368, 112-113 (1902)

H. Fukunishi, Y. Takahashi, M. Sato et al., Geophys. Res. Lett. 24, 2973 (1997)

M. Füllekrug, E. A. Mareev, M. J. Rycroft, editors, Sprites, Elves and Intense Lightning

Discharges (Springer, Dordrecht, 2006), 398pp

P. Galison, Image and Logic: A material culture of microphysics (University of Chicago Press,

Chicago, 1997)

H. Gerdien, Nachr. von der Ges. der Wiss. zu Gött. 1903, 383-399 (1903)

H. Gerdien, Nachr. von der Ges. der Wiss. zu Gött. 1904, 277-299 (1904)

H. Gerdien, Nachr. von der Ges. der Wiss. zu Gött. 1905, 258-270 (1905a)

H. Gerdien, Nachr. von der Ges. der Wiss. zu Gött. 1905, 447-458 (1905b)

O.H. Gish, K.L. Sherman, 'Electrical Conductivity of Air to an Altitude of 22 Kilometres', in Nat.

Geogr. Soc. Techn. Papers, Stratosphere Series, No. 2, Washington, DC (1936)

A. Gockel, Phys Z. 4, 871 (1903)

R. Grard, M. Hamelin, J.J. López-Moreno et al, Planet. Space Sci. 54, 1124-1136 (2006)

R.G. Harrison, K.L. Aplin, Atmos. Env., 36, 25, 4037-4043 (2002)

R.G. Harrison, K.L. Aplin, Atmos. Env., 37, 38, 5319-5324, doi: 10.1016/j.atmosenv.2003.09.042 (2003)

R.G. Harrison, A.J. Bennett, J. Atmos. Sol. Terr. Phys. 69, 515-527, doi:10.1016/j.jastp.2006.09.008. (2007)

R.G. Harrison, A.J. Bennett, Adv. Geosci. 13, 17-23 (2007)

R.G. Harrison, Surv. Geophys. 25, 441 (2004)

R.G. Harrison, Space Sci. Rev., 94, 381-396 (2000) 
R.G. Harrison, K. S. Carslaw, Rev. Geophys., 41, doi: 10.1029/2002RG000114 (2003)

R.G. Harrison, F. Märcz, Geophys. Res. Lett. 34, L23816, doi:10.1029/2007GL031714 (2007)

R.G. Harrison, K.P. Shine, A review of recent studies of the influence of solar changes on the Earth's climate. Hadley Centre Technical Note 6 (Met Office, Exeter, UK, 1999)

O. Heaviside in: Encyc. Brit.10th (London, 1902) 9 pp 213-218.

V.F. Hess, Phys. Z.. 13, 1084 (1912)

M. Hesse, in A Companion to the Philosophy of Science, ed. by W. H. Newton-Smith (Blackwell, Oxford, 2000), pp 299-307

I.M. Imyanitov, E.V Chubarina, Electricity of the free atmosphere (Israel program for Scientific Translations, Jerusalem, 1967)

G.H. Jones, N. Krupp, H. Krüger, et al, Geophys. Res. Lett. 33, L21202, doi:10.1029/2006GL028146 (2006)

A.K. Kamra, M. Ravichandran, J.Geophys. Res., 98, D12, 22,875-22,885 (1993)

A.E. Kennelly, Electr. World Eng., 32, 473 (1902)

B. Lovell, Notes Rec. Roy. Soc. Lond., 51, 1, 151-153 (1997)

W. Lowrie, Fundamentals of Geophysics, $2^{\text {nd }}$ edn. (Cambridge University Press, Cambridge, 2007) pp. 274-276

F. Märcz, J Geophys. Res. 81, 25, 4566 (1976)

R. Markson, Nature 273, 103 (1978)

R. Markson, Bull. Amer. Meteor. Soc. 88, 1 (2007)

A. McAdie, Science, 61, 1586, 540 (1925)

A. Mika, C. Haldoupis, Space Sci. Rev, this issue (2008)

E. Mishin, G. Milikh, Space Sci. Rev, this issue (2008)

R.P. Mülheisen, Pur. App. Geophys. 84, 112-115 (1971)

R.P. Mülheisen, in Electrical Processes in Atmospheres, ed. by H. Dolezalek, R. Reiter, (Steinkopf

Verlag, Darmstadt, 1977), pp467-476

N. Olsen, A. Kuvshinov, Earth Planets Space 56, 525 (2004)

N. R. Owen, K.L. Aplin, P.A. Stevens, J. Phys. Conf. Ser. (in press, 2007)

V.P.Pasko, M.A.Stanley, J.D.Mathews, U.S.Inan, T.G.Woods, Nature 416, 152 (2002)

J. Read, Phil. Trans. Roy. Soc. Lond., 81, 185-212 (1791)

R.G. Roble, I. Tzur, in The Earth's Electrical Environment, ed. by E.P. Krider, R.G. Roble,

(National Academy Press, Washington DC, 1986), pp206-231.

M. J. Rycroft, J. Atmos. Sol.-Terr. Phys. 68, 445 (2006)

M. J. Rycroft, M. Füllekrug, J. Atmos. Sol-Terr. Phys. 66, 1103 (2004)

M. J. Rycroft, A. Odzimek, N. F. Arnold et al., J. Atmos.Sol.-Terr.Phys. doi

10.1016/j.jastp.2007.09.004 (2007)

M.J. Rycroft et al, Space Sci. Rev, this issue, 2008

C.P.R. Saunders, Space Sci. Rev, this issue, 2008

W.B. Schiffer, Draw the lightning down: Benjamin Franklin and electrical technology in the age of enlightenment (University of California Press, Berkeley, 2003) pp1-11

W.O. Schumann, Z. Naturforsch. A, 7, 149-154 (1952)

W.O. Schumann, H. König, Naturwiss., 41, 183-184 (1954)

R. W. Schunk, A. F. Nagy, Ionospheres - Physics, Plasma Physics and Chemistry, (Cambridge

University Press , Cambridge, 2000) pp. 553

F. Simoes, R. Grard, M. Hamelin et al, Planet. Space Sci. 55 1978-1989

doi:10.1016/j.pss.2007.04.016 (2007)

F. Simoes et al, Space Sci. Rev, this issue (2008)

G.C. Simpson, Phil Trans. Roy. Soc. A 205, 61-97 (1906a).

G.C. Simpson, Mon. Wea. Rev, 34, 1, 16-17 (1906b)

G.C. Simpson, Phil Trans. Roy. Soc. A, 209, 379-413 (1909)

G.C. Simpson, Geogr. J., 97, 6 383-385 doi:10.2307/1788175 (1941)

H.T.Su, R.R.Hsu, A.B.Chen et al., Nature 423, 974 (2003)

W. Thomson, Report of $29^{\text {th }}$ meeting, British Association for the Advancement of Science, Aberdeen (1859).

B. A. Tinsley, R. P. Rohrbaugh, M. Hei et al, J. Atmos. Sci., 57, 2118-2134 (2000)

B. A. Tinsley, R. P. Rohrbaugh, M. Hei, Atmos. Res. 59-60, 115-135 (2001)

B. A. Tinsley, Space Sci. Rev., 94, 1-2, 231-258 (2000)

S.N. Tripathi, Removal of Charged Aerosols, PhD Thesis, The University of Reading, UK (2000)

S.N. Tripathi, R.G. Harrison, Atmos Res 62 57-70 (2002)

S.N. Tripathi, S. Vishnoi, S. Kumar et al, Q..J. Roy. Met. Soc., 132, 1717 (2006)

J. Tuma, Sitz. Ak. Wiss. Wien, 227-260 (1899)

L. Wahlin, J. Geophys. Res. 99, D5, 10,767 (1994) 
F.J.W. Whipple, Q..J. Roy. Met. Soc., 55, 351(1929)

F.J.W. Whipple, F. J. Scrase, Met. Off. Geophys. Mem. 68 (1936)

A. Wigand, Terr. Mag. Atm. Elect, 19, 93-101 (1914)

A. Wigand, Annalen der Physik, 60, 18, 81-109 (1921)

E. R. Williams, in Encyclopedia of Atmospheric Sciences, ed. by J. R. Holton, J. A. Pyle, J. A. Curry (Academic, New York, 2002), pp. 724-733

E. R. Williams, Proc. $13^{\text {th }}$ Int. Conf. Atm. Elect., Beijing, China, August $13^{\text {th }}-17$ th $(2007)$

E. R. Williams, S. J. Heckman, J. Geophys. Res. 98, D3, 5221 (1993)

C. T. R. Wilson, Phil. Trans. Roy. Soc. Lond. A., 189, 265-307 (1897)

C. T. R. Wilson, Phil. Trans. Roy. Soc. Lond. A., 189, 403-453 (1899)

C. T. R. Wilson, Proc. Camb. Phil. Soc. 13, 364 (1906)

C. T. R. Wilson, Proc. Roy. Soc. Lond. A. 80, 542, 537-547 (1908)

C. T. R. Wilson, Notebook entitled "Thunderstorms; Condensation" ref CW/A/9 (1908-1912)

C. T. R. Wilson, Phil. Trans. Roy. Soc. Lond. A, 221, 73 (1921)

C. T. R. Wilson, Notebook entitled "Atmospheric electricity" ref CW/B/7 (1926)

C. T. R. Wilson, J. Franklin Inst. 208, 1, 1-12 (1929)

Y. Yair, Space Sci. Rev, this issue (2008)

F. Yu, R. P. Turco, J. Geophy. Res., 106, D5, 4797-4814, doi: 10.1029/2000JD900539 (2001)

B. Zolss, Phys Z., 5, 106, (1904) 
Table 1 Summary of the early European research balloon flights in atmospheric electricity listing quantities measured by different investigators (after Harrison and Bennett, 2007). (Atmospheric Electricity $(\mathrm{AE})$ quantities: $\mathrm{PG}=$ Potential Gradient, surface air conductivity $\sigma_{0}$, positive air conductivity $\sigma_{+}$, negative air conductivity $\sigma_{-}$, air temperature $T$, relative humidity $R H$ ). Hess's 1912 ascent measured ion production, not atmospheric electrical quantities, but is significant because this flight discovered cosmic rays.

\begin{tabular}{|c|c|c|c|c|c|c|c|c|c|c|}
\hline \multirow[b]{2}{*}{ Investigator } & \multirow[b]{2}{*}{ Launch date } & \multirow[b]{2}{*}{ Launch site } & \multirow{2}{*}{$\begin{array}{r}\text { Max } \\
\text { height } \\
(m)\end{array}$} & \multicolumn{4}{|c|}{ AE quantities } & \multicolumn{2}{|c|}{ Met data } & \multirow[t]{2}{*}{ Source } \\
\hline & & & & PG & $\sigma_{0}$ & $\sigma_{+}$ & $\sigma_{-}$ & $\mathrm{T}$ & RH & \\
\hline Tuma & $\begin{array}{l}1892,1894\left(22^{\text {nd }}\right. \\
\text { Sep }) ; 7 \text { flights } 1894 \\
\text { to } 1898\end{array}$ & Near Salzburg & 3000 & $\checkmark$ & & & & $\checkmark$ & $\checkmark$ & $\begin{array}{c}\text { Chauveau } \\
\text { 1925; Tuma } \\
1899 \\
\end{array}$ \\
\hline Le Cadet & $\begin{array}{l}1893\left(1^{\text {st }} \text { and } 9^{\text {th }}\right. \\
\text { Aug) }\end{array}$ & $\begin{array}{c}\text { Meudon- } \\
\text { Valhermay, } \\
\text { Paris }\end{array}$ & 2520 & $\checkmark$ & & & & & & Andre 1893 \\
\hline Börnstein & 1893 & Berlin & & $\checkmark$ & & & & & & $\begin{array}{c}\text { Chauveau } \\
1925\end{array}$ \\
\hline Gerdien & $\begin{array}{l}1903\left(1^{\text {st }} \text { July, } 2^{\text {nd }}\right. \\
\text { Aug, } 1^{\text {st }} \text { Oct, } 5^{\text {th }} \\
\text { Nov })\end{array}$ & $\begin{array}{l}\text { Göttingen and } \\
\text { Berlin }\end{array}$ & 7100 & & & \multicolumn{2}{|c|}{$\mu_{ \pm} \mathrm{n}_{ \pm}$} & & $\checkmark$ & Gerdien 1903 \\
\hline Gerdien & $\begin{array}{l}1903\left(14^{\text {th }} \text { April }\right) \\
1904\left(5^{\text {th }} \text { May }\right), \\
1905\left(11^{\text {th }} \text { May, }\right. \\
\left.30^{\text {th }} \text { Aug }\right)\end{array}$ & $\begin{array}{l}\text { Charlottenberg } \\
\text { (Berlin) }\end{array}$ & 6030 & $\checkmark$ & & $\checkmark$ & $\checkmark$ & & $\checkmark$ & $\begin{array}{l}\text { Gerdien 1904; } \\
\text { Gerdien } \\
\text { 1905a; } \\
\text { Gerdien 1905b }\end{array}$ \\
\hline Hess & 1912 (7th Aug) & Aussig & 5000 & \multicolumn{4}{|c|}{ Ion production rate } & & & Hess 1912 \\
\hline Wigand & $\begin{array}{l}1913\left(12^{\text {th }} \text { and } 27^{\text {th }}\right. \\
\text { July, } 4^{\text {th }} \text { Aug, } 9^{\text {th }} \\
\text { Sep })\end{array}$ & Bitterfeld & 9005 & $\checkmark$ & $\checkmark$ & $\checkmark$ & $\checkmark$ & $\checkmark$ & $\checkmark$ & $\begin{array}{c}\text { Wigand 1914, } \\
\text { 1921; Everling } \\
\text { and Wigand } \\
1921 \\
\end{array}$ \\
\hline Wigand & $1919\left(18^{\text {th }} \mathrm{Dec}\right)$ & $?$ & 2950 & $\checkmark$ & & $\checkmark$ & $\checkmark$ & & & $\begin{array}{l}\text { Everling and } \\
\text { Wigand } 1921\end{array}$ \\
\hline $\begin{array}{c}\text { Gish } \\
\text { Explorer } 2\end{array}$ & 1935 (11 $1^{\text {th }}$ Nov $)$ & South Dakota & 22000 & & & \multicolumn{2}{|c|}{$\checkmark$} & $\checkmark$ & & $\begin{array}{c}\text { Gish and } \\
\text { Sherman } 1936\end{array}$ \\
\hline
\end{tabular}

Table 2 Necessary conditions for a global circuit in a planetary atmosphere, and which of them could be determined from different measurements (indicated with a tick). The merging of two cells indicates that two measurements could determine one parameter.

\begin{tabular}{|l|c|l|c|c|c|}
\hline condition & \multicolumn{2}{|l|}{ Charge generation } & $\begin{array}{l}\text { Lower } \\
\text { conductive } \\
\text { surface }\end{array}$ & $\begin{array}{l}\text { Upper } \\
\text { conductive } \\
\text { surface }\end{array}$ & $\begin{array}{l}\text { Vertical } \\
\text { current } \\
\text { flowing }\end{array}$ \\
\hline $\begin{array}{l}\text { measurement } \\
\text { discharges }\end{array}$ & $\begin{array}{l}\text { Plectrical } \\
\text { resonamant }\end{array}$ & $\checkmark$ & $\checkmark$ & $\checkmark$ & \\
\hline $\begin{array}{l}\text { Atmospheric } \\
\text { electric field }\end{array}$ & \multicolumn{2}{|c|}{$\checkmark^{8}$} & & & \multirow{2}{*}{${ }^{9}$} \\
\hline $\begin{array}{l}\text { Electrical } \\
\text { conductivity }\end{array}$ & & & & & \\
\hline Radar & & $\checkmark$ & $\checkmark$ & & \\
\hline $\begin{array}{l}\text { Broadband } \\
\text { radio }\end{array}$ & $\checkmark$ & & & & \\
\hline Optical & $\checkmark$ & & & & \\
\hline
\end{tabular}

\footnotetext{
${ }^{8}$ If measurements are made on rapid timescales

${ }^{9}$ If Ohm's Law is obeyed, i.e. little mechanical transport of aerosol particles
} 
Figure 1 Essential features of the global atmospheric electric circuit, from Rycroft and Füllekrug(2004).

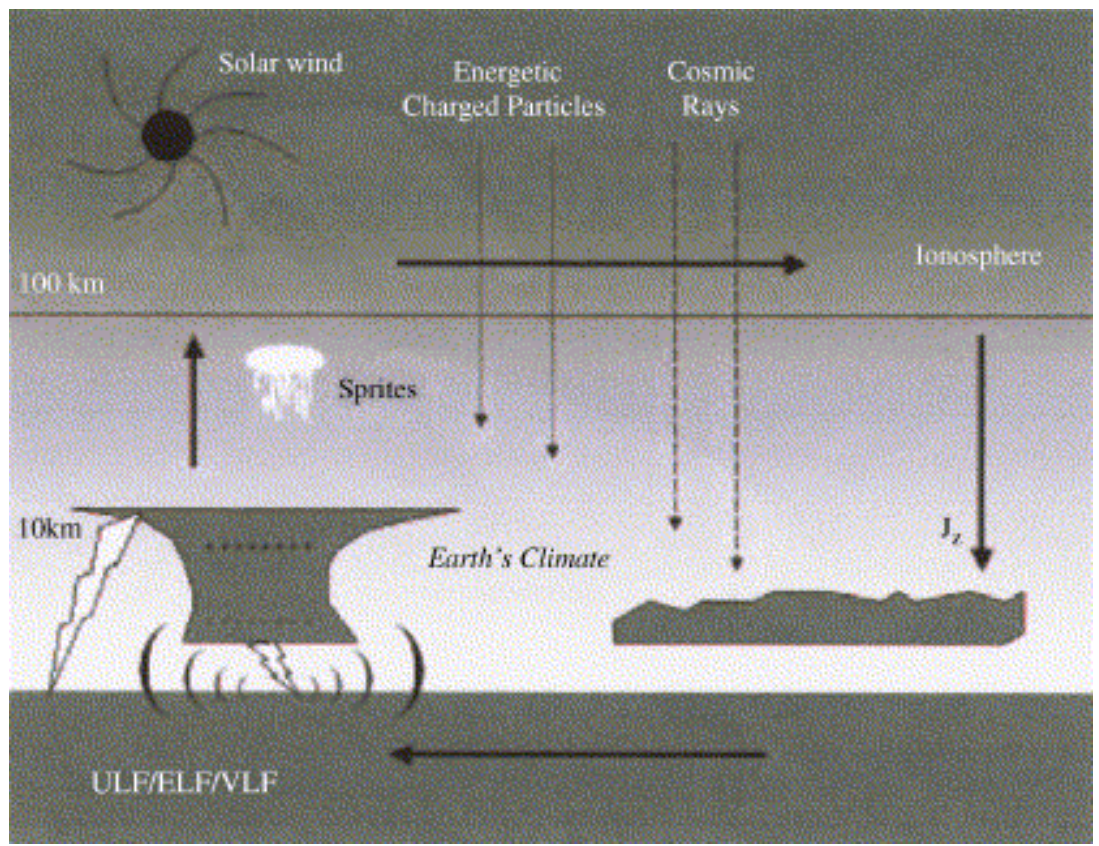

Figure 2 Simplified “electrical engineering” model of the global circuit, illustrating charge generation in disturbed weather regions, conduction through the ionosphere (upper layer) and surface (lower layer), and discharge through the finite conductivity of fair weather regions. In fair weather regions, the ionospheric potential $V_{\mathrm{i}}$, conduction current density $J_{\mathrm{c}}$ and unit area columnar resistance $R_{\mathrm{c}}$ are related by Ohm's Law.

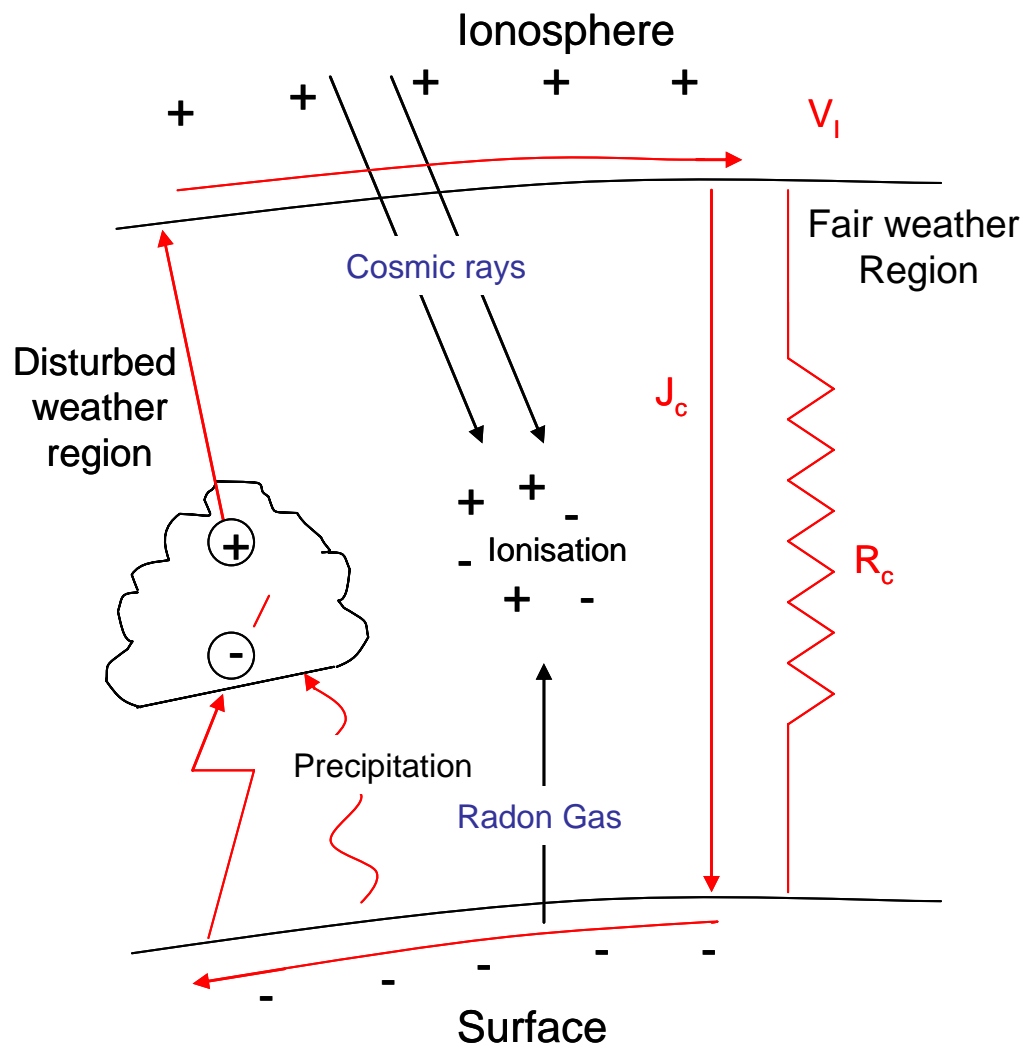


Figure 3 Nucleation of ultrafine condensation nuclei (UCN), catalysed by ions from water or sulphuric acid vapour in the atmosphere, which could grow into cloud condensation nuclei (CCN). Reproduced with permission from AAAS from Carslaw et al. (2002).

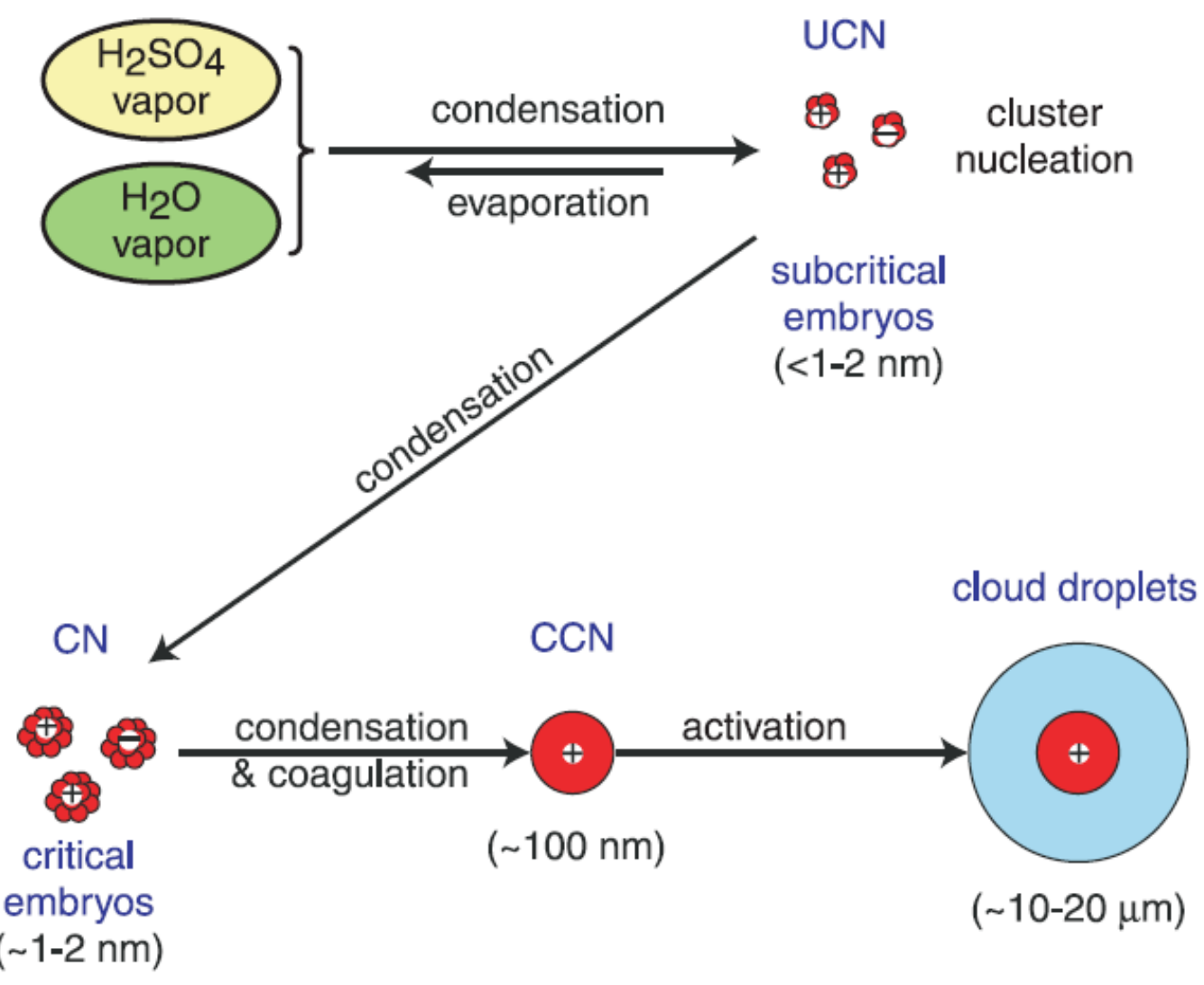

Figure 4 Electric charge distributed around an isolated cloud in the fair weather part of the global circuit. The upward electric field is shown at the right hand side. From Harrison and Carslaw (2003).

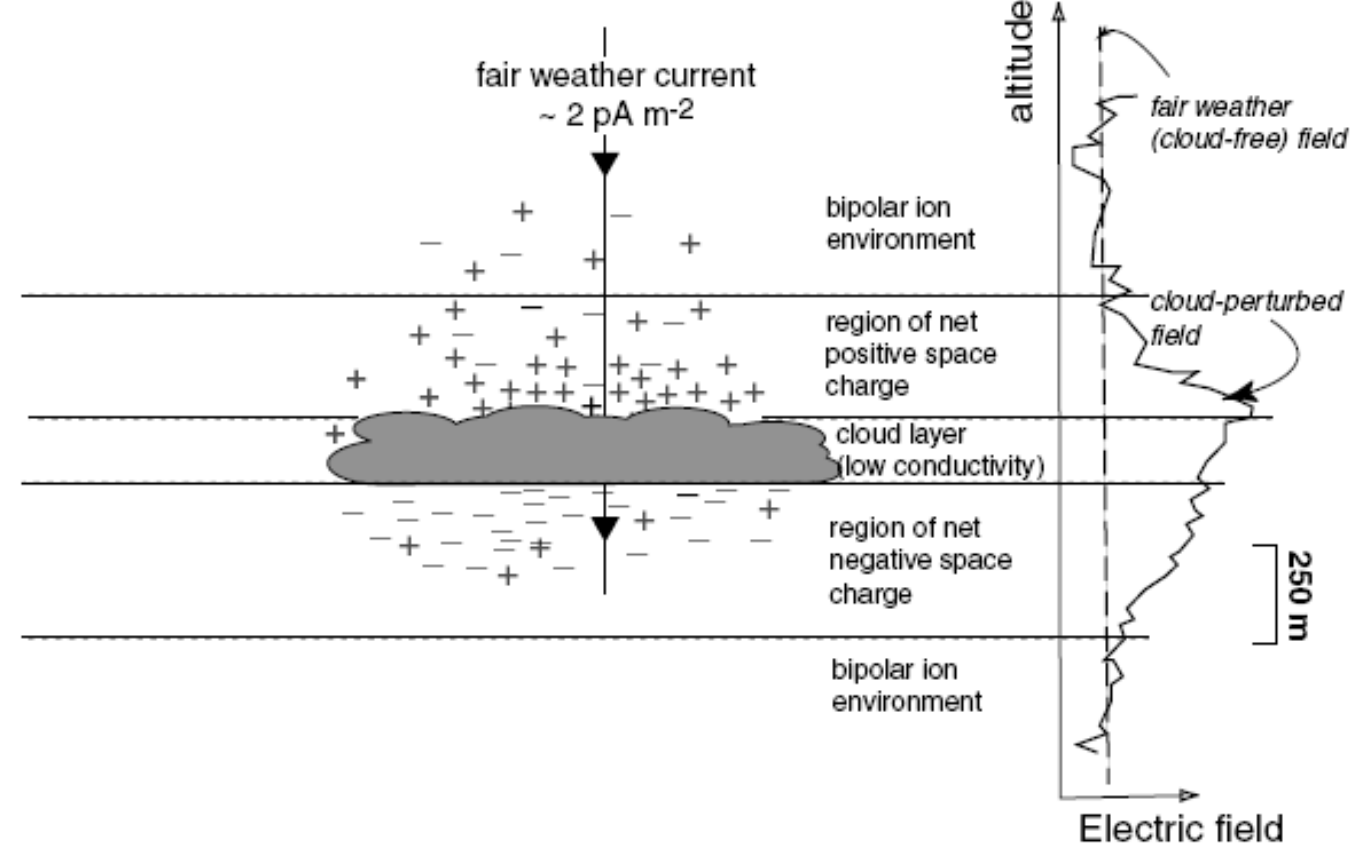


